\title{
CMRO
}

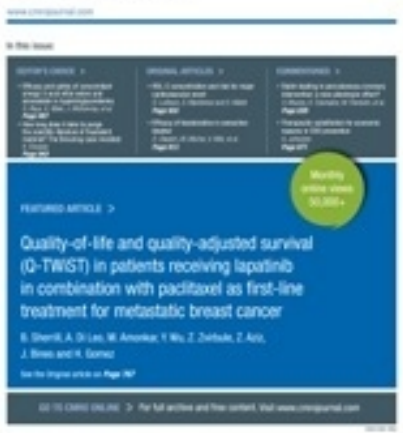

\section{Availability of post-trial access in clinical trials: a review of clinical trial protocols submitted to the Research Ethics Board of the University of the Philippines Manila}

\begin{tabular}{|r|l|}
\hline Journal: & Current Medical Research \& Opinion \\
\hline Manuscript ID & CMRO-2019-ST-0097.R1 \\
\hline Manuscript Type: & Original Article \\
\hline Dute Submitted by the \\
Author: & n/a \\
\hline Keywords: $\begin{aligned} \text { List of Authors: } \\
\text { Jimenez, Edlyn; University of the Philippines Manila, National Institutes } \\
\text { of Health } \\
\text { Virtudazo, Jessa Mae; University of the Philippines - Manila, Research } \\
\text { Ethics Board } \\
\text { Torres, Cristina; University of the Philippines Manila, National Institutes } \\
\text { of Health } \\
\text { Bernabe, Rosemarie; University of Oslo, Faculty of Medicine; University } \\
\text { Medical Center Utrecht, Julius Center for Health Sciences and Primary } \\
\text { Care }\end{aligned}$ \\
\hline & \begin{tabular}{l} 
bost-trial access, post-trial obligations, clinical trials, research ethics \\
\hline
\end{tabular} \\
\hline
\end{tabular}

\section{SCHOLARONE Manuscripts}


Availability of post-trial access in clinical trials: a review of clinical trial protocols submitted to the Research Ethics Board of the University of the Philippines Manila Edlyn B Jimenez ${ }^{\mathrm{a}}$, Jessa Mae P Virtudazo ${ }^{a}$, Cristina E Torres ${ }^{\mathrm{a}}$, Rosemarie DLC Bernabe ${ }^{\mathrm{b}}$

\section{Abstract}

Ethics guidelines such as the Declaration of Helsinki and the CIOMS International Ethical Guidelines for Health-related Research Involving Humans require the sponsors, in cooperation with relevant stakeholders, to provide post-trial access (PTA) to intervention and knowledge, especially in clinical trials held in resource-poor regions. To date, we have very limited knowledge in terms of whether PTA is provided at all, and in what form. To partially address this current limitation, this study wished to explore whether, for which type of drugs, and in what form PTA is provided in the Philippines.

We looked at all the clinical trial protocols submitted to the University of the Philippines Manila from 2012 to 2017. A total of 193 clinical trial protocols were included in the study. To identify whether, for which drug type, and in what form PTA is provided, we gathered the following information: start and end date of the trial, name of study drug, tested indication of the study drug, region the sponsor is from, type/category of the study drug, type of funding agency, provisions for PTA (yes or no), and the explanation for the provisions. PTA provisions were further described to determine what form PTA was provided and which types of drug were given PTA.

Of the 193 protocols, $51.81 \%$ indicated PTA, the most common form being the provision or sharing of information (40 protocols). None of the protocols provided PTA in the form of access to intervention after the trials, with the possible exemption of 10 protocols that declared future evaluation of the sponsor for PTA depending on patient need, and another seven that might offer the option to transfer to an open-label extension study after the trial. More work is needed if PTA, as stipulated in ethics guidelines, is to be reflected in reality.

Keywords: post-trial obligations, post-trial access, research ethics, clinical trials

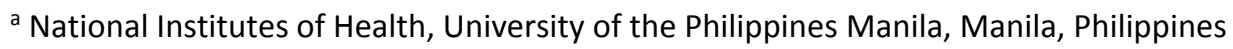

${ }^{b}$ Corresponding author, email: r_bernabe@yahoo.com. Centre for Medical Ethics, Institute of Health and Society, University of Oslo, Norway.
} 


\section{Introduction}

Clinical trials are moving quickly from high income to low and middle income countries (LMICs) [1-3]. In the EU, the number of clinical trials submitted to the European Medicines Agency (EMA) for marketing authorization applications from the rest of the world region (ROW) tripled from 2005 to 2011 [4], and has overtaken the number of such clinical trials from the EU and North America since 2011 [4].

The globalization of clinical trials may be explained by several factors, the most prominent of which are cost savings [2]; shorter recruitment timelines [2,5]; and less stringent regulatory constraints $[2,5]$. That clinical trials are conducted for these reasons is not necessarily ethically problematic if, aside from the usual ethics requirements of informed consent and ethics committee review, these trials contribute to increased access to essential and innovative medicines in the region. The conduct of clinical trials can have a role in increasing access to medicines if, specifically, and in terms of ethics guidelines, post-trial access (PTA) is in place. The Declaration of Helsinki Article 20, for example, states the following:

Medical research with a vulnerable group is only justified if the research is responsive to the health needs or priorities of this group and the research cannot be carried out in a non-vulnerable group. In addition, this group should stand to benefit from the knowledge, practices or interventions that result from the research [6].

The CIOMS International Ethical Guidelines for Health-related Research Involving Humans provides more guidance on "research conducted in resource-poor settings":

As part of their obligation, sponsors, and researchers must also: make every effort, in cooperation with government and other relevant stakeholders, to make available as soon as possible any intervention or product developed, and knowledge generated, for the population or community in which the research is carried out, and to assist in building local research capacity [7].

While PTA is stipulated in the guidelines, it is another concern whether such stipulation is in fact in effect. The provision of post-trial access to research participants is mandated by law in various degrees in a few countries, such as in Argentina, Brazil, Chile, Finland, and Peru [8]. Through a study of corporate best practices based on corporate responses to a survey, we also know that the provision of PTA, even in LMICs, is sponsor-defined, i.e., sponsors are at liberty to provide PTA or not [9]; that it is mostly provided in "exceptional circumstances" (i.e., the situation is life-threatening; discontinuing treatment would result to adverse effect on health of the participant; no local alternative treatment; and a positive benefit-risk balance of the safetyefficacy of the treatment) [9]; and that PTA is narrowly defined to refer to the provision of yet non-licensed drugs to patient-participants [9]. However, though previous studies point to the weaknesses of the implementation of PTA, we still do not know the rate that PTA is provided, if at all, whether in exceptional circumstances or not. The only study we know that looked at the 
rate of PTA was a nonprobability qualitative study of 34 protocols submitted to the Mexican Sub-Commission for Ethics in Research in 2004, the results of which showed that PTA was not considered in any of the cases [10]. Though this research points to a specific direction, i.e., that PTA is not provided, we cannot know for sure that PTA was in fact not present, considering that this was a qualitative study. Since saturation point was used to choose the 34 protocols and not the entire population or at least a statistical sampling, we could not, with certainty, state that there indeed were no PTA provisions in the other protocols submitted within the said year. Also, we expected to see some trend. Lastly, we would also probably wish to look at PTA provisions in more than one LMIC. To add to the body of knowledge on the rate of PTA, our study intended to explore whether, for which type of drugs, and in what form PTA is provided in the Philippines.

Our study aimed to, at least, partially address the limitations in the literature by looking at all Research Ethics Board (UPMREB) from 2012 to 2017. These years would sufficiently document changes in PTA provision trend, if any, from the year of the latest version of the Declaration of Helsinki (2013) and the 2016 version of the CIOMS Ethics Guidelines. UPMREB data on PTA provisions is interesting for at least three reasons: 1) the Philippines is top three contributor in Asia in terms of the number of patients in pivotal clinical trials submitted to the EMA for marketing authorization application [4]; 2) UP Manila has a good cross section of multi-center pharmaceutical trials conducted in the Philippines; and lastly, 3) according to a January 2018 TrialTrove search, UP Manila has the most number of clinical trial investigators nationally, and second in the country in terms of the number of international clinical trials. In the Philippines, the major research ethics committees are all recognized by the Forum for Ethical Review Committees in the Asian and Western Pacific Region and accredited by the Philippine Health Research Ethics Board; hence, the procedures, standards, and requirements of the major research ethics committees are comparable.

The study was submitted to the UPMREB for review and was granted exemption from ethical review. A total of 193 clinical trial protocols were included in the study. PTA information is explicitly required in protocol submission to the UPMREB. The protocol template requires the investigator to indicate whether or not the protocol has PTA provision stated in the informed consent document, with an option to indicate that PTA is not applicable. To identify whether, for which drug type, and in what form PTA is provided, we gathered the following information from these protocols: start and end date of the trial, name of study drug, tested indication of the study drug, region the sponsor is from, type/category of the study drug, type of funding agency, provisions for PTA (yes or no), and the explanation for the provisions. From the Excel file, we then made a count of the number of protocols submitted to UPMREB per year, 
104 categorized the study drugs based on indication and the US new drug application (NDA)

105 classification ${ }^{c}$.

106 We counted the 'yes' responses on the question whether the trial provides PTA. We then

107 collated their statements on PTA provision and categorized them to identify in what form PTA

108 was provided. Lastly, to identify for which types of drugs PTA was provided, we grouped PTA

109 provisions based on drug types based on indication and NDA classification.

\section{Results}

\section{Number of trials and types of study drugs}

112 The clinical trials were categorized based on the condition/disease that the clinical trial is 113 studying. Most of the study drugs were meant to address non-communicable diseases

114 (76.17\%), most of which were for respiratory, neoplastic, and cardiovascular diseases (see Table 1151 below).

\begin{tabular}{|c|c|}
\hline List of Diseases & Number of Clinical Trials \\
\hline \multicolumn{2}{|l|}{ NON-COMMUNICABLE DISEASES } \\
\hline Respiratory & 30 \\
\hline Neoplasms & 21 \\
\hline Cardiovascular & 18 \\
\hline Mental/neurological & 17 \\
\hline Autoimmune Diseases & 16 \\
\hline Diabetes and Kidney & 15 \\
\hline Pain & 8 \\
\hline Musculoskeletal Disorder & 6 \\
\hline Skin disease & 5 \\
\hline Sense organ & 3 \\
\hline Digestive diseases & 2 \\
\hline Genetic disease & 2 \\
\hline Others & 2 \\
\hline Urinary disease & 1 \\
\hline Anemia & 1 \\
\hline TOTAL & $147(76.17 \%)$ \\
\hline \multicolumn{2}{|l|}{ COMMUNICABLE DISEASES } \\
\hline Bacterial/viral (vaccine) & 29 \\
\hline Other bacterial & 11 \\
\hline Other viral & 2 \\
\hline Fungal infection & 1 \\
\hline Respiratory tract infection & 3 \\
\hline TOTAL & $46(23.83 \%)$ \\
\hline
\end{tabular}

\footnotetext{
${ }^{c}$ The classification is as follows: Type 1: new molecular entity; Type 2; new active ingredient; Type 3: new dosage form; Type 4: new combination; Type 5: new formulation or other differences (e.g., new indication, new applicant, new manufacturer); Type 6: new indication or claim, same applicant; Type 7: previously marketed but within an approved NDA; Type 8: Rx to over-the-counter; Type 9: new indication or claim, not to be marketed under Type 9 NDA after approval; Type 10: new indication or claim, drug to be marketed under Type 10 NDA after approval[11].
} 
116 Table 1: Condition/disease addressed by clinical trials in UPM, 2012-2017

117 In terms of types of study drugs, most of the study drugs were new combinations, new 118 molecular entities, and new formulations (see Figure 1).

\section{TYPES OF STUDY DRUGS}

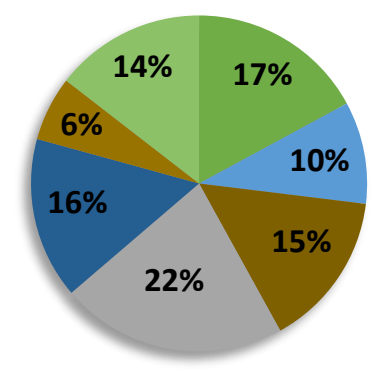

new molecular entity

New active ingredient

new dosage form

new combination

new formulation

- New indication Type 9 NDA

New indication Type 10 NDA

Figure 1: Types of study drugs in clinical trials in UPM, 2012-2017

121 The clinical trials were predominantly sponsor-initiated studies from pharmaceutical companies 122 in North America, Europe, and Asia (in descending order in terms of number of trials; see Figure 123 2). Note that no local trials were documented.

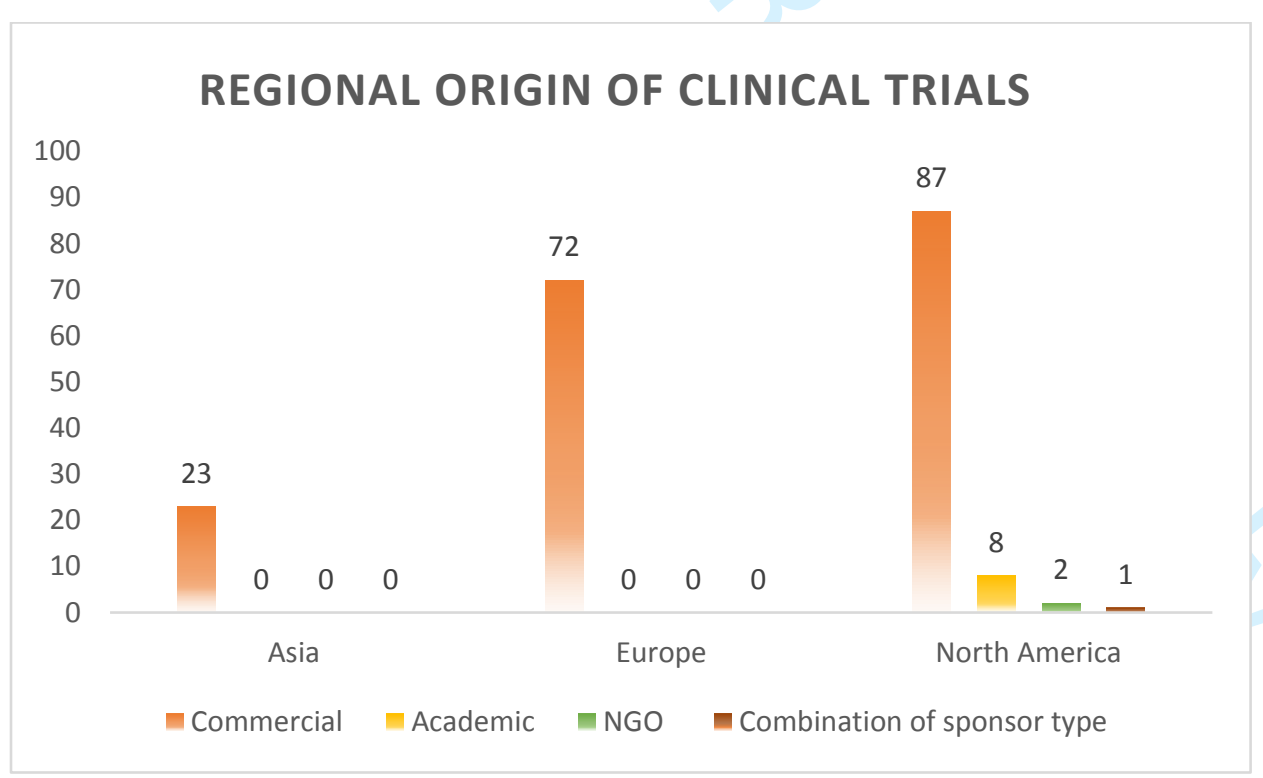

124

125

126

127

128

129

130

Figure 2: Sponsor origin of clinical trials in UPM, 2012-2017

\section{Post-trial Access Provisions}

Among the 193 protocols reviewed from 2012 to 2017, 100 (51.81\%) protocols indicated some form of post-trial provision, while $93(48.19 \%)$ indicated that PTA is not applicable. The proportion of protocols with and without the indication of post-trial provisions remains approximately similar across the different clinical trial regional origins (Figure 3 ). This trend is 
131 relatively consistent throughout the years (Figure 4), in spite of the declining trend in clinical 132 trial submissions.

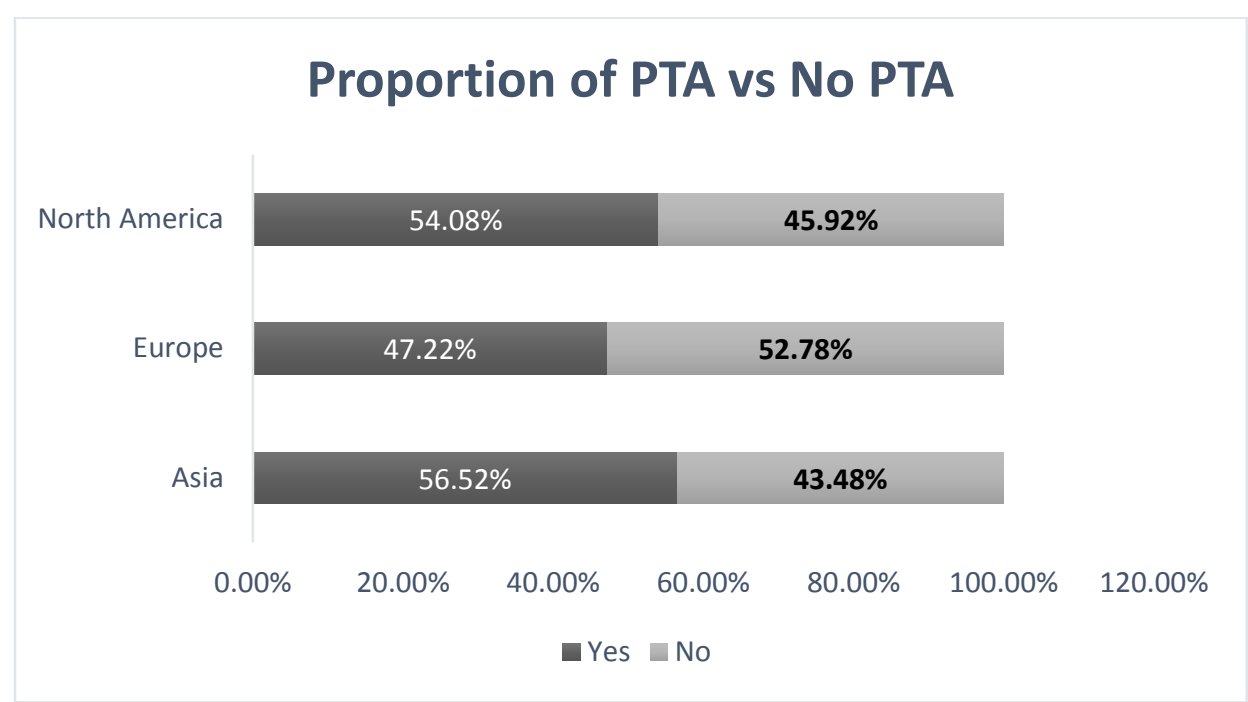

133 134

Figure 3: Proportion of clinical trials that indicated PTA versus those without a PTA indication

\section{PTA Provisions Across 6 years}

$120.00 \%$

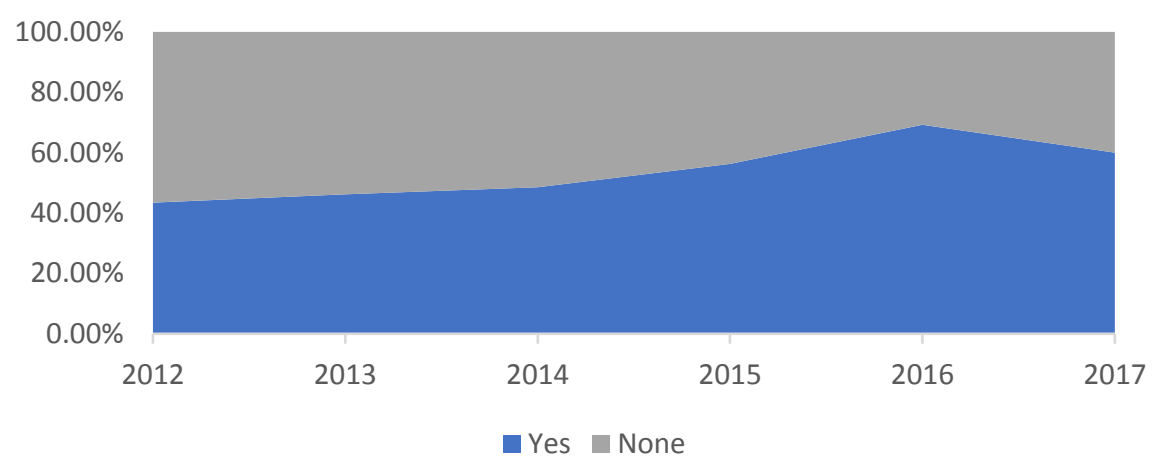

Figure 4: Proportion of clinical trials that indicated PTA versus those without a PTA indication, 2012-2017

When these 100 protocols with indications of PTA were grouped according to type of study drug (Figure 5), the trend is comparatively similar to the total number of clinical trials grouped according to study drug type in Figure 1, i.e., most of the PTA indications were in new combinations and new molecular entities. 


\section{Type of Study Drug (with PTA)}

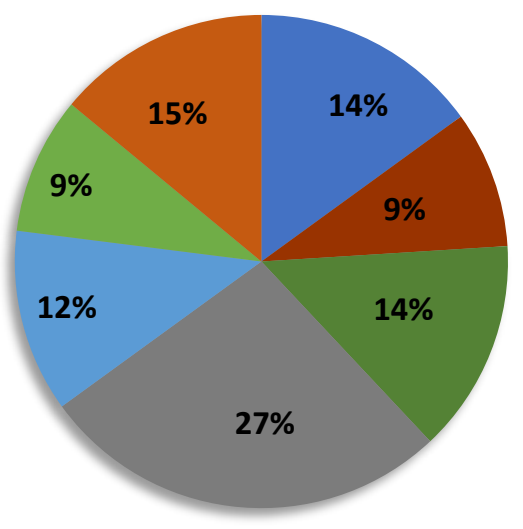

- New molecular entity

- New active ingredient

new dosage form

new combination

new formulation

- New indication Type 9 NDA

new indication Type 10 NDA

142

144 Among the protocols that indicated a post-trial provision, the PTA identified by the sponsors 145 may be categorized as follows: (1) access to trial results (including registries) or information; (2) 146 presence of standard of care outside the trial; (3) no PTA of the study drug will be provided; (4) 147 PTA to be evaluated by sponsor depending on patient need; (5) unknown benefit owing to 148 experimental nature of the study; (6) drug will be made/is available in the market; (7) option to 149 transfer to open-label extension study; and (8) during-study access to study drug (Table 2). 


\section{Type of Provisions by Year Submitted}

\begin{tabular}{|c|c|c|c|c|c|c|c|c|}
\hline \multicolumn{9}{|c|}{$\begin{array}{l}\text { Option to transfer to open-label extension study } \\
\text { Availability of drug in the market }\end{array}$} \\
\hline \multicolumn{9}{|c|}{ Unknown benefit owing to experimental nature } \\
\hline \multicolumn{9}{|c|}{ Evaluated by sponsor depending on patient need } \\
\hline \multicolumn{9}{|c|}{ Study will not have post-trial access } \\
\hline \multicolumn{9}{|c|}{ Standard of care outside of trial } \\
\hline \multicolumn{9}{|c|}{ Access to results (including registries) or information } \\
\hline & & & & 5 & 10 & 20 & 30 & 35 \\
\hline & $\begin{array}{l}\text { Access to } \\
\text { results } \\
\text { (including } \\
\text { registries) or } \\
\text { information }\end{array}$ & $\begin{array}{l}\text { Standard of } \\
\text { care outside } \\
\text { of trial }\end{array}$ & $\begin{array}{l}\text { Study will not } \\
\text { have post- } \\
\text { trial access }\end{array}$ & $\begin{array}{l}\text { Evaluated by } \\
\text { sponsor } \\
\text { depending } \\
\text { on patient } \\
\text { need }\end{array}$ & $\begin{array}{c}\text { Unknown } \\
\text { benefit } \\
\text { owing to } \\
\text { experimental } \\
\text { nature }\end{array}$ & $\begin{array}{l}\text { Availability of } \\
\text { drug in the } \\
\text { market }\end{array}$ & $\begin{array}{l}\text { Option to } \\
\text { transfer to } \\
\text { open-label } \\
\text { extension } \\
\text { study }\end{array}$ & $\begin{array}{l}\text { During-study } \\
\text { access to } \\
\text { study drug }\end{array}$ \\
\hline$\square 2012$ & 8 & 4 & 1 & 5 & 1 & 1 & 0 & 0 \\
\hline - 2013 & 7 & 1 & 2 & 4 & 0 & 3 & 1 & 0 \\
\hline 2014 & 12 & 1 & 2 & 1 & 0 & 1 & 0 & 0 \\
\hline E 2015 & 5 & 6 & 1 & 0 & 4 & 1 & 1 & 0 \\
\hline E 2016 & 8 & 1 & 3 & 0 & 2 & 2 & 1 & 1 \\
\hline 2017 & 0 & 3 & 1 & 0 & 1 & 0 & 4 & 0 \\
\hline
\end{tabular}

151

152

153

154

155

156

157

158

159

160

161

162

163

164

165

Table 2: Type of provisions by year of clinical trials submitted to UP Manila

In Table 2, the most commonly indicated PTA is access to results, including publication of results in a clinical trial registry or in medical journals, or the sharing of information, including safety information and other information that could potentially be useful in clinical decisionmaking. After access to information, the next commonly indicated PTA is the availability of standard of care outside of the trial as an alternative to trial participation. In practice, the IRB actively seeks the PTA provision only when the disease is rare or incurable or treatment is very expensive, and only when the results are effective and safe.

\section{Discussion}

The results of this study must be viewed in terms of the requirements of ethics guidelines, specifically of the Declaration of Helsinki and CIOMS, as quoted above. Helsinki requires the sharing of knowledge, practices, or interventions; however, this declaration is silent on when PTA is relevant to which type of study. CIOMS provides more clarity in this matter, specifically, that PTA is (1) the responsibility of the sponsor in cooperation with the government and other 
relevant stakeholders; and (2) this responsibility consists in making the product developed and knowledge generated to be available as soon as possible to the population or community where the research was carried out.

The Declaration of Helsinki provision on post-trial access describes post-trial obligations as providing access to appropriate care or to relevant information after research [6]. In the literature, access to appropriate care has been interpreted to mean affordable access or "reasonable availability of beneficial pharmaceuticals or medical treatments" [12]; continued access to study interventions that have demonstrated significant benefit and for transitioning participants who continue to need care and preventive measures after the research to appropriate health services [13]; or an obligation to facilitate sustainable access or subsidized access to new interventions in host communities [14].

In our study, several of the types of declared PTA by the sponsors showed that some sponsors either have their own definition of PTA that is different from what ethics guidelines provide, different from what the literature refers to as appropriate care, or that the sponsors have no idea what ethics guidelines or the literature say about PTA. The following PTA categories are either not in agreement with the ethical definition of PTA or are directly opposed to it: (1) presence of standard of care outside the trial; (2) no PTA of the study drug will be provided; (3) unknown benefit owing to experimental nature of the study; (4) drug will be made or is available in the market; and (5) during-study access to study drug.

The literature suggests that the practice of providing PTA differs across countries and contexts. The example of Brazil and Argentina, for example, refer to PTA as access to the interventional drug of the patient participants after the trial and so long as they need it and before access to other means becomes available [8]. This type of PTA was not directly observed in our study, though the $5 \%$ (i.e., 10 of the 193) of the studies where PTA will be evaluated by the sponsor based on patient-participants' needs could lead to this sort of access. At the same time, PTA may also mean the transition of the patient-participants into extension studies sponsored by pharmaceutical manufacturers until the intervention becomes available in the health system $[13,15,16]$, though admittedly this is not always possible [17]. This was the case for $4 \%$ (i.e., 7 of the 193) of the clinical trials in our study. Lastly, the provision of PTA may also mean incorporating in the trial design the continued access to a proven beneficial intervention (e.g. WHO recommendations that PTA, in terms of availability of the vaccine to the community, be a requirement before conducting a clinical trial on a respiratory syncytial virus vaccine in LMICs) [18]. This type of PTA was not observed in our study.

The number of protocols that indicated PTA (51.81\%) among the clinical trials reviewed seemed encouraging, at first. However, when we considered the types of PTA declared by the sponsors, we realized that the most that the population or community might get is information that may be clinically relevant in the future (40 protocols). In addition, there were seven protocols which might offer patient-participants the option to transfer to an open-label extension study, plus the 10 where PTA will be evaluated by the sponsor post-trial. In practice, sponsors provide 
205

206

207

208

209

210

211

212

213

214

215

216

217

218

219

220

221

222

223

224

225

226

227

228

229

230

231

232

233

234

235

236

237

238

239

240

241

242

post-trial access through follow-up studies to see long term effects on patients, open label extension studies, expanded access, and compassionate use, among others [9]. At best, these drugs are made available on a case to case basis [9] and not as a standard requirement to comply with the Declaration of Helsinki and CIOMS.

Out of the 100 protocols with post-trial provisions, there were 10 where the sponsor declared the future evaluation of PTA depending on patient need. This means that in all instances, none of the sponsors made PTA arrangements before the beginning of the study. Recall that CIOMS stipulates that before undertaking research in a community or population with limited resources, sponsors and investigators must "make every effort to ensure that any intervention or product developed, or knowledge generated, will be made reasonably available for the benefit of that population or community." From the perspective of CIOMS, only the 40 protocols that declared information sharing as PTA partially complied with the PTA imperative, and depending on how the sponsor decides on the situation, maybe the 17 others, too, who might consider PTA after sponsor evaluation or provide PTA in the form of an open-label follow up study. All others did not comply with PTA requirements at all.

According to another study, pharmaceutical companies mostly provide PTA in "exceptional circumstances" (i.e., the situation is life-threatening; discontinuing treatment would result to adverse effect on health of the participant; no local alternative treatment; and a positive benefit-risk balance of the safety-efficacy of the treatment) [9]. Even when we narrowly define PTA this way, apparently none of the protocols saw the situation as exceptional enough to consider PTA pre-trial, and only 10 declared possible PTA subject to sponsor evaluation. This is a cause for concern because, first, at least some of the study drugs were meant to address diseases that could be life threatening such as the various kinds of neoplastic diseases or severe respiratory, autoimmune, or cardiovascular diseases. Second, we also know that a big proportion of the patient-participants of the trials in UPM were likely to discontinue with treatment, especially for very costly drugs, for several poverty-related reasons: there is no universal access to health care in the Philippines and health care is usually out of pocket; poverty rate is currently at $21.6 \%$ [19]; and the Philippine General Hospital of the UPM, as a public hospital, usually caters to patients who are unable to afford private hospitals.

Assuming that the study showed positive benefit/risk balance of efficacy-safety of the study drug, all the corporate indicators of what is "exceptional" seemed present in at least some of the studies. Since sponsors are usually aware of this situation, it must further be explored why none of the protocols considered PTA arrangements pre-trial, on the condition that there is positive benefit-risk balance of the safety-efficacy profile of the study drug, and only 10 indicated this probability subject to sponsor evaluation. Literature offers to explain noncompliance to PTA. According to Wang and Ferraz, commitment to post-trial obligations may be onerous and may impede future research, regardless of who will be sponsoring these obligations, as it may redirect costs from funding other potential studies such as chronic and 
243 rare diseases [20]. Whether this reason holds from an economic perspective remains to be 244 seen.

245 To date, none of the clinical trial protocols evaluated by UPMREB fully complied with ethical 246 requirements for PTA. Through no fault of the IRB, there remains a lack of standardized governance to implement post-trial obligations [21]. If PTA is to be fully reflected in reality, clearly more work has to be done in terms of clarification of what the term means (i.e., what must be provided, in what manner, to what extent); ensuring common understanding of the term among the various stakeholders; a PTA-encouraging environment; and a structure that facilitates stakeholder cooperation for PTA.

\section{Conclusion}

More than half (100 out of 193) of the clinical trials submitted in UPMREB indicated post-trial provisions and the most common post-trial access provision identified is access to information. Post-trial access will be dependent upon the evaluation of the sponsor based on patient need and the option to transfer to open-label extension study in ten (5\%) and seven (4\%) clinical trials, respectively. It can be deduced that none of the sponsors made PTA arrangements pretrial, and at best, are made available on a case to case basis. This result is alarming since these clinical trials involved life-threatening diseases, and especially for researches conducted in LMICs where there is no adequate access to marketed drugs and even to universal health care, patients may not be able to access these drugs after the trial ends. As such, post-trial access to study drugs remains a challenge. There are existing guidelines stipulating post-trial obligations but there is poor compliance among the pharmaceutical sponsors. Furthermore, despite the CIOMS and Helsinki provisions on post-trial access, there seems to be no international consensus around it. Based on its current status, achieving post-trial access, as stipulated in ethics guidelines, would need further and considerable work.

\section{Declaration}

268 The research leading to these results has received funding from the European Union Seventh 269 Framework Programme (FP7-PEOPLE-2013-COFUND) under grant agreement $n^{\circ} 609020$ -

\section{Scientia Fellows.}

\section{References:}

272 [1] Eccard R, Amato AA, Guilhem DB, Rita M, Garbi C, Silva RE. Globalization of clinical trials : ethical and regulatory implications. Int J Clin Trials (Internet). 2016;3(1):1-8. Available from: http://www.ijclinicaltrials.com/index.php/ijct/article/view/103

\section{[2] Glickman SW, McHutchison JG, Peterson ED, Cairns CB, Harrington RA, Califf RM, et al.} Ethical and Scientific Implications of the Globalization of Clinical Research. N Engl J Med (Internet). 2009;360[9]:816-23. Available from: http://www.nejm.org/doi/abs/10.1056/NEJMsb0803929

[3] Jeong S, Sohn M, Kim JH, Ko M, Seo H won, Song YK, et al. Current globalization of drug interventional clinical trials: Characteristics and associated factors, 2011-2013. Trials. 
2017;

[4] European Medicines Agency. Clinical trials submitted in marketing authorization applications to the European Medicines Agency: overview of patient recruitment and the geographical location of investigator sites (Internet). 2013. Available from: http://www.ema.europa.eu/docs/en_GB/document_library/Other/2009/12/WC500016 819.pdf

[5] Wemos Foundation. A bitter pill: the risks of carrying out clinical trials in developing countries (Internet). Amsterdam; 2008. Available from: https://www.wemos.nl/wpcontent/uploads/2017/04/A_Bitter_Pill_2008.pdf

[6] Association WM. Declaration of Helsinki - ethical principles for medical research involving human subjects (Internet). 2013 (cited 2015 Apr 20). Available from: http://www.wma.net/en/30publications/10policies/b3/

[7] Council for International Organizations of Medical Sciences. International ethical guidelines for health-related research involving humans (Internet). 2016. Available from: https://cioms.ch/shop/product/international-ethical-guidelines-for-health-relatedresearch-involving-humans/

[8] da Silva RE, Amato AA, Sousa TdR, de Carvalho MR, Novaes MRCG. The patient's safety and access to experimental drugs after the termination of clinical trials: regulations and trends. European Journal of Clinical Pharmacology. 2018.

[9] Schipper I. Post-trial access to treatment: corporate best practices (Internet). Amsterdam; 2015. Available from: http://www.somo.nl/publicationsen/Publication_4169

[10] Páez R, De Alba JEG. International research and just sharing of benefits in Mexico. Dev World Bioeth. 2009;9(2):65-73.

[11] US Center for Drug Evaluation and Research. NDA Classification Codes (Internet). 2015. Available from: https://www.fda.gov/downloads/AboutFDA/CentersOffices/OfficeofMedicalProductsan dTobacco/CDER/ManualofPoliciesProcedures/UCM470773.pdf

[12] Cook K, Snyder J, Calvert J. Attitudes toward post-trial access to medical interventions: A review of academic literature, legislation, and international guidelines. Developing World Bioethics. 2015.

[13] Paul A, Merritt MW, \& Sugarman J. Implementing post-trial access plans for HIV prevention research. 2018.

[14] Pratt B, Zion D, Lwin KM, Cheah PY, Nosten F, Loff B. Linking international clinical research with stateless populations to justice in global health. BMC Medical Ethics. 2014;15:49. Available from: https://www.ncbi.nlm.nih.gov/pmc/articles/PMC4085396/pdf/1472-6939-15-49.pdf

[15] Doval DC, Shirali, R, Sinha R. Post-trial access to treatment for patients participating in clinical trials. Perspectives in Clinical Research. 2015;6(2): 82-85.

[16] Usharani P, Nagyi, SMH. Post-trial access. Perspectives in Clinical Research. 2013;4(1):58-60. Available from: https://www.ncbi.nlm.nih.gov/pmc/articles/PMC4394585/

[17] Dainesi SM, Goldbaum M. Post-trial access to study medication: a Brazilian e-survey with major stakeholders in clinical research. Journal of Medical Ethics. 2012. 
325 [18] Mazur NI, Bont L, van Delden JJM, Omer SB. An ethics framework and practical 326 guidance for post-trial access to an RSV maternal vaccine. 2019. The Lancet Respiratory Medicine.

[19] Asian Development Bank. Poverty in the Philippines (Internet). 2018. Available from: https://www.adb.org/countries/philippines/poverty

[20] Wang DWL, and Ferraz OLM. Pharmaceuitcal companies vs the State: Who is responsible for post-trial provision of drugs in Brazil? 2012. Journal of Law, Medicine \& Ethics.

[21] Mastroleo, I. Post-trial obligations in the Declaration of Helsinki 2013: Classification, reconstruction, and interpretation. 2015. 
1 Availability of post-trial access in clinical trials: a review of clinical trial protocols submitted to 2 the Research Ethics Board of the University of the Philippines Manila

3 Edlyn B Jimenez $z_{\alpha}^{a}$ Jessa Mae P Virtudazo ${ }^{a}$, Cristina E Torres ${ }^{a}$, Rosemarie DLC Bernabeb

6 Abstract

7 Ethics guidelines such as the Declaration of Helsinki and the CIOMS International Ethical 8 Guidelines for Health-related Research Involving Humans require the sponsors, in cooperation 9 with relevant stakeholders, to provide post-trial access (PTA) to intervention and knowledge, 10 especially in clinical trials held in resource-poor regions. To date, we have very limited 1 knowledge in terms of whether PTA is provided at all, and in what form. To partially address 12 this current limitation, this study wished wishes, to explore whether, for which type of drugs, and 13 in what form PTA is provided in the Philippines.

14 We looked at all the clinical trial protocols submitted to the University of the Philippines Manila 15 from 2012 to 2017. A total of 193 clinical trial protocols were included in the study. To identify 16 whether, for which drug type, and in what form PTA is provided, we gathered the following 17 information: startbegin and end date of the trial, name of study drug, tested indication of the 18 study drug, region the sponsor is from, type/category of the study drug, type of funding agency, 19 provisions for PTA (yes or no), and the explanation for the provisions. PTA provisions were 20 further described to determine what form PTA was provided and which types of drug were 21 given for PTA.
Formatted: Font: $12 \mathrm{pt}$

Formatted: Font: $12 \mathrm{pt}$
Formatted: Font: $12 \mathrm{pt}$
Formatted: Font: $12 \mathrm{pt}$
Formatted: Font: $12 \mathrm{pt}$
Formatted: Font: $12 \mathrm{pt}$

Formatted: Font: $12 \mathrm{pt}$

Formatted: Font: $12 \mathrm{pt}$

Formatted: Font: $12 \mathrm{pt}$

Formatted: Font: $12 \mathrm{pt}$

Formatted: Font: $12 \mathrm{pt}$

Formatted: Font: $12 \mathrm{pt}$

Formatted: Font: 12 pt

\footnotetext{
a National Institutes of Health, University of the Philippines, Manila, Manila, the Philippines

${ }^{b}$ Corresponding author, email: r_bernabe@yahoo.com. Centre for Medical Ethics, Institute of Health and Society, University of Oslo, Norway.
} 


\section{Introduction}

Clinical trials are moving quickly moving from high income to low and middle income countries (LMICs) [(1-3)] - In the EU, the number of clinical trials submitted to the European Medicines Agency (EMA) for marketing authorization applications from the rest of the world region (ROW) tripled from 2005 to 2011 [ $[4]]_{2}$, and since 2011 has overtaken the number of such clinical trials from the EU and North America since 2011][t4]t.

The globalization of clinical trials may be explained by several factors, the most prominent of

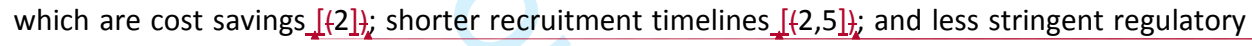
constraints $[(2,5]$. That clinical trials are conducted for these reasons is not necessarily ethically problematic if, aside from the usual ethics requirements of informed consent and ethics committee review, these trials contribute to increased access to essential and innovative medicines in the region. The conduct of clinical trials can have a role in increasing access to medicines if, specificallyspecifically, and in terms of ethics guidelines, that post-trial access (PTA) is in place. The Declaration of Helsinki Article 20, for example, states the following:

Medical research with a vulnerable group is only justified if the research is responsive to the health needs or priorities of this group and the research cannot be carried out in a non-vulnerable group. In addition, this group should stand to benefit from the knowledge, practices or interventions that result from the research $[$ ( 6$]$ t.

The CIOMS International Ethical Guidelines for Health-related Research Involving Humans provides a more guidance on "research conducted in resource-poor settings":

As part of their obligation, sponsors, and researchers must also: make every effort, in cooperation with government and other relevant stakeholders, to make available as soon as possible any intervention or product developed, and knowledge generated, for the population or community in which the research is carried out, and to assist in building local research capacity $[$ [ 7$]+$.

While PTA is stipulated in the guidelines, it is another concern whether such stipulation is in fact in effect. The provision of post-trial access to research participants is mandated by law in various degrees in a few countries, such as in Argentina, Brazil, Chile, Finland, and Peru [8]. Now, it is one thing that PTA is stipulated in the guidelines and quite another on whether such stipulation is in fact in effect. To date, we know only of one country with PTA legislation, i.e., Brazill(8). Through a study of corporate best practices based on corporate responses to a survey, we also know that the provision of PTA, even in LMICs, is sponsor-defined, i.e., sponsors are atef liberty to provide PTA or not [9] (8); that it is mostly provided in "exceptional circumstances" (i.e., the situation is life-threatening; discontinuing treatment would result to adverse effect on health of the participant; no local alternative treatment; and a positive benefit-risk balance of the safetyefficacy of the treatment) [9](8); and that PTA is narrowly defined to refer to the provision of yet non-licensed drugs to patient-participants [9](8). However, though previous studies point his study points to the weaknesses of the implementation of PTA, we still do not know the

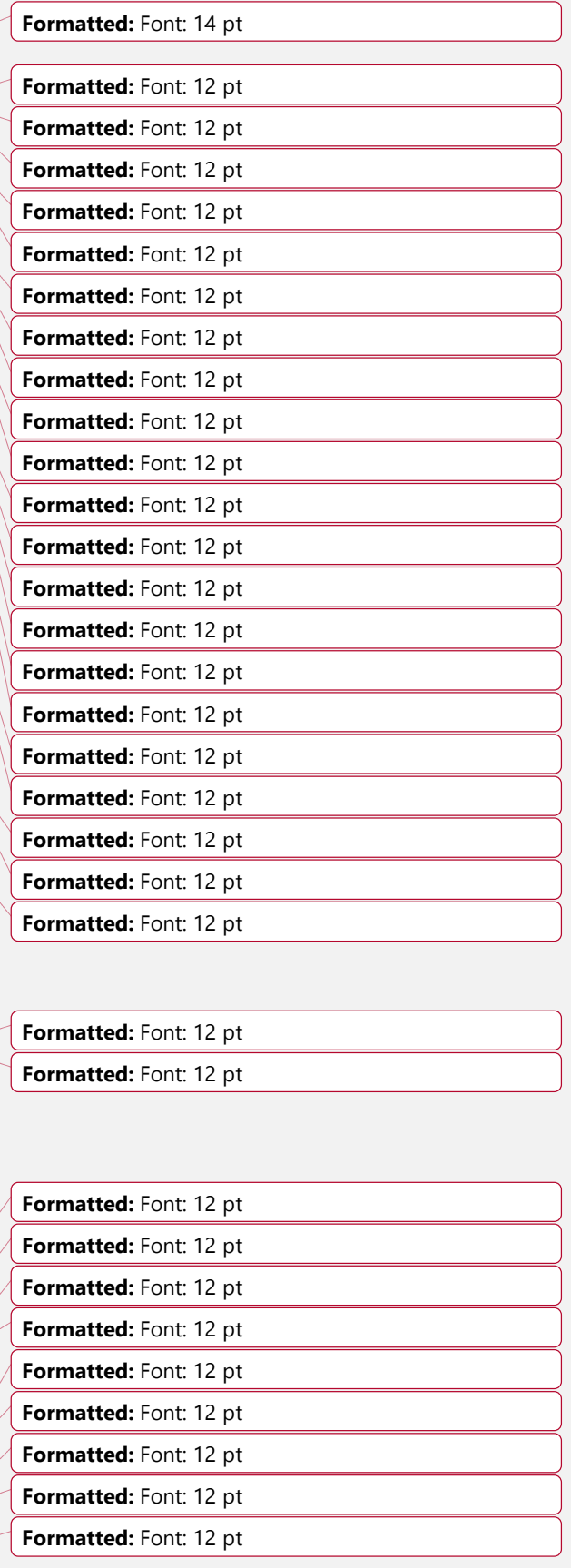

Formatted: Font: $14 \mathrm{p}$

Formatted: Font: $12 \mathrm{pt}$

Formatted: Font: $12 \mathrm{p}$

Formatted: Font: $12 \mathrm{pt}$

Formatted: Font: $12 \mathrm{pt}$

Formatted: Font: $12 \mathrm{pt}$

Formatted: Font: $12 \mathrm{pt}$

Formatted: Font: $12 \mathrm{pt}$

Formatted: Font: $12 \mathrm{pt}$

Formatted: Font: $12 \mathrm{pt}$

Font: $12 \mathrm{pt}$

Formatted: Font: $12 p$

Formatted: Font: $12 \mathrm{pt}$

Formatted: Font: $12 \mathrm{pt}$

Formatted: Font: $12 \mathrm{pt}$

Formatted: Font: $12 \mathrm{pt}$

Formatted: Font: $12 \mathrm{pt}$

Formatted: Font: $12 \mathrm{pt}$

Formatted: Font: $12 p$

Formatted: Font: $12 \mathrm{pt}$

Formatted: Font: $12 \mathrm{pt}$ 
rate that PTA is provided, if at all, whether in exceptional circumstances or not. The only study we know that looked at the rate of PTA was a nonprobabilitynomilistic qualitative study of 34 protocols submitted to the Mexican Sub-Commission for Ethics in Research in 2004, the results of which showed that PTA was not considered in any of the cases [10](9). Though this research points to a specific direction, i.e., that PTA is not provided, we cannot know for sure that PTA was in fact not present, considering that this was a qualitative study. SinceBecause, saturation point was used to choose the 34 protocols and not the entire population or at least a statistical sampling, we could not ${ }_{4}$ with certainty, state-say that there indeed were no PTA provisions in the other protocols submitted within the said year. Also, we expected robably wish to see some trend. Lastly, we would also probably wish to look at PTA provisions in more than one LMIC. To add to the body of knowledge on the rate of PTA, our study intendedwishes to explore whether, for which type of drugs, and in what form PTA is provided in the Philippines.

\section{Methodology}

83 Our study aimed sishes to $_{4}$ at least ${ }_{4}$ partially address the limitations in the literature by looking 84 at all the international clinical trial protocols submitted to the Research Ethics Board of the 85 University of the Philippines Manila Research Ethics Board (UPMREB(UPA-REB) from 2012 to 86 2017. These years would sufficiently document changes in PTA provision trend, if any, from the 87 year of the latest version of the Declaration of Helsinki (2013) and the 2016 version of the 88 CIOMS Ethics Guidelines. UPMREB data on PTA provisions is interesting for at least three 89 reasons: 1)the Philippines is top three contributor in Asia in terms of the number of patients in 90 pivotal clinical trials submitted to the EMA for marketing authorization application [ $[4]+2$; 2) UP 91 Manila has a good cross_-section of multi-center pharmaceutical trials conducted in the Philippines; and lastly, 3) according to a January 2018 TrialTrove search, UP Manila has the most number of clinical trial investigators nationally ${ }_{4}$ and second in the country in terms of the number of international clinical trials. In the Philippines, the major research ethics committees are all recognizedaccredited by the Forum for Ethical Review Committees in the Asian and Western Pacific Region ${ }_{\overline{4}}$ and accredited by the Philippine Health Research Ethics Board; hence ${ }_{4}$ the procedures, standards, and requirements of the major research ethics committees are comparable.

The study was submitted to the UPMREB for review and was granted exemption from ethical review. A total of 193 clinical trial protocols were included in the study. PTA information is explicitly required in protocol submission to the UPMREBUPM-REB. The protocol template requires the investigator to indicate whether or not the protocol has PTAa post-trialaccess provision stated in the informed consent document, with an option to indicate that PTApost trial access is not applicable. To identify whether, for which drug type, and in what form PTA is provided, we gathered the following information from these protocols: startbegin and end date of the trial, name of study drug, tested indication of the study drug, region the sponsor is from, type/category of the study drug, type of funding agency, provisions for PTA (yes or no), and the

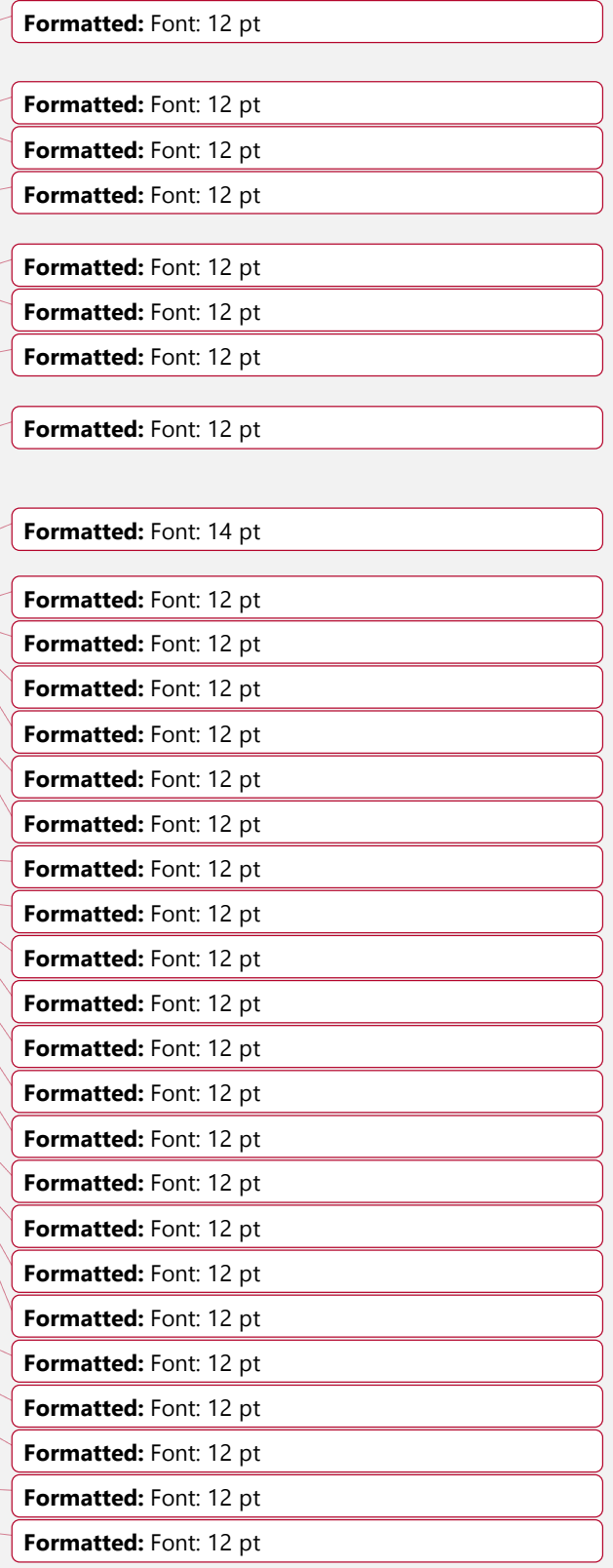


explanation for the provisions. From the Excel file, we then made a count of the number of protocols submitted to UPMREBUPA-REB per year, categorized the study drugs based on indication and the US new drug application (NDA) classificationc.

WeTokn whether PTA is provided, we counted the 'yes' responses on the question, whether the trial provides PTA. We then collated their statements on PTA provision and categorized them to identify in what form PTA was provided. Lastly, to identify for which types of drugs PTA was provided, we grouped PTA provisions based on drug types based on indication and NDA classification.

\section{Results}

\section{$117 \quad$ Number of trials and types of study drugs}

118 The clinical trials were categorized based on the condition/disease that the clinical trial is 119 studying. Most of the study drugs were meant to address non-communicable diseases 120 121 122 123 124 125
$(76.17 \%)$, most of which were for respiratory, neoplastic, and cardiovascular diseases (see Table 1 below).

The 193 protocols, when categorized based on submission year, shows a downward trend in terms of submissions: 46 (24\%) protocols were submitted in 2012, $39(20 \%)$ in 2013, 35(18\%) in 2014, 32 (17\%) in 2015, 26(13\%) in 2016, and 15 (8\%) in 2017. These trials have varying durations ranging from less than 1 year to 9 years. Majority (75.13\%) of the clinical trials range from 1 to 3 years (Table 1 ).

\begin{tabular}{r|r}
\multicolumn{1}{|c|}{ List of Diseases } & Number of Clinical Trials \\
\hline NON-COMMUNICABLE & \\
DISEASES & \\
Respiratory & 30 \\
Neoplasms & 21 \\
Cardiovascular & 18 \\
Mental/neurological & 17 \\
Autoimmune Diseases & 16 \\
Diabetes and Kidney & 15 \\
Musculoskeletal Disorder & 8 \\
Skin disease & 6 \\
Sense organ & 5 \\
Digestive diseases & 3 \\
\hline
\end{tabular}

' The classification is as follows: Type 1: new molecular entity; Type 2; new active ingredient; Type 3: new dosage form; Type 4: new combination; Type 5: new formulation or other differences (e.g., new indication, new applicant, new manufacturer); Type 6: new indication or claim, same applicant; Type 7: previously marketed but within an approved NDA; Type 8: Rx to over-the-counter; Type 9: new indication or claim, not to be marketed under Type 9 NDA after approval; Type 10: new indication or claim, drug to be marketed under Type 10 NDA after approval[f11]t.

\begin{tabular}{l} 
Formatted: Font: $12 \mathrm{pt}$ \\
Formatted: Font: $12 \mathrm{pt}$ \\
Formatted: Font: $12 \mathrm{pt}$ \\
Formatted: Font: $12 \mathrm{pt}$ \\
Formatted: Font: $12 \mathrm{pt}$ \\
Formatted: Font: $12 \mathrm{pt}$, Italic \\
\hline
\end{tabular}


Table 1: Duration of UPA clinical trials

In terms of the condition/disease that the clinical trialis studying, most of the study drugs are meant to address noncommunicable diseases (76.17\%), most of which are for respiratory, neoplastic, and eardiovascular diseases (see Table 2).

\section{Condition/disease addressed by clinicalUPA, trials in UPM, 2012-2017}

In terms of types of study drugs, most of the study drugs wereare new combinations, new molecular entities, and new formulations (see Figure 1).

\section{TYPES OF STUDY DRUGS}

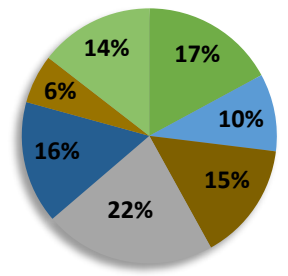

new molecular entity

New active ingredient

- New dosage form

new combination

- New formulation

- New indication Type 9 NDA

New indication Type 10 NDA

Figure 1: Types of study drugs in UPA-clinical trials in UPM, 2012-2017

The clinical trials wereare predominantly sponsor-initiated studies from pharmaceutical companies infrom North America, Europe, and Asia (in descending order in terms of number of trials; see Figure 2). Note that no local trials were documented.
Formatted: Font: $12 \mathrm{pt}$

Formatted: Font: $12 \mathrm{pt}$

Formatted: Font: $12 \mathrm{pt}$

Formatted: Font: $12 \mathrm{pt}$

Formatted: Font: $12 \mathrm{pt}$ 


\section{Proportion of PTA vs No PTA}

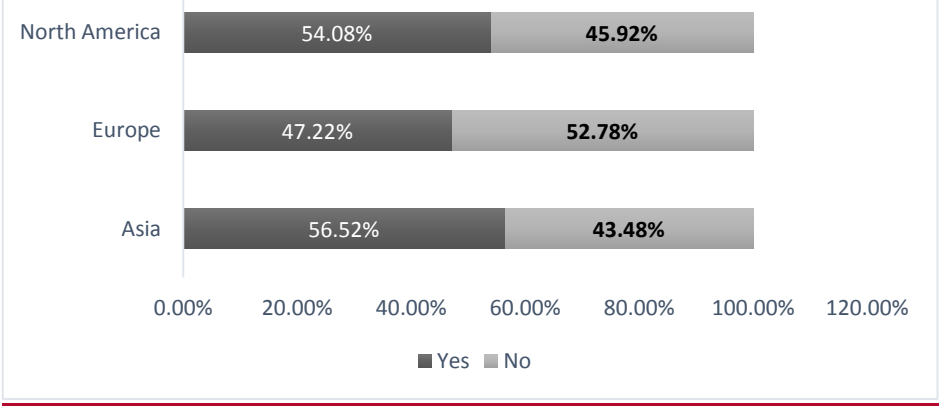

Formatted: Font: $12 \mathrm{pt}$

Formatted: Font: $12 \mathrm{pt}$

Formatted: Font: $12 \mathrm{pt}$

Formatted: Font: $12 \mathrm{pt}$

Formatted: Font: $12 \mathrm{pt}$

Formatted: Font: $12 \mathrm{pt}$ 
$\begin{array}{ll}161 & \text { Among the protocols that indicated a post-trial provision, the PTA identified by the sponsors } \\ 162 & \text { may be categorized as follows: }(1) \text { access to trial results (including registries) or information; }(2) \\ 163 & \text { presence of standard of care outside the trial; }(3) \text { no PTA of the study drug will be provided; }(4)\end{array}$

161 Among the protocols that indicated a post-trial provision, the PTA identified by the sponsors
162 may be categorized as follows: $(1)$ access to trial results (including registries) or information; $(2)$
163 presence of standard of care outside the trial; (3) no PTA of the study drug will be provided; $(4)$

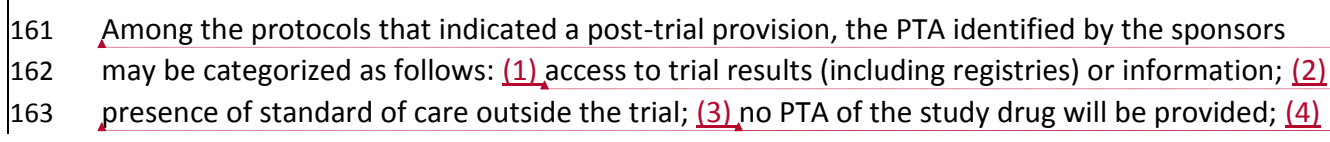

Figure 4: Proportion of clinical trials that indicated PTA versus those without a PTA indication, 2012-2017

When these 100 protocols with indications of PTA wereare grouped according to type of study drug (Figure 5), the trend is comparativelysomet similar to the total number of clinical trials grouped according to study drug type in Figure 1, i.e., most of the PTA indications wereare in new combinations and new molecular entities.

\section{Type of Study Drug (with PTA)}

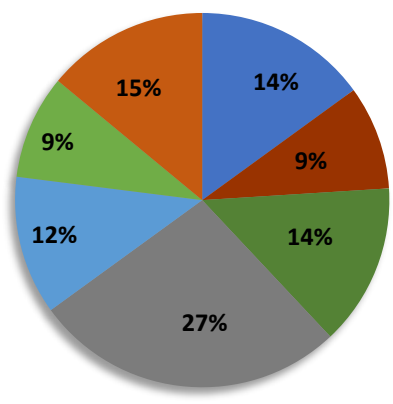

- New molecular entity

- New active ingredient

- New dosage form

- New combination

new formulation

- New indication Type 9 NDA

New indication Type 10 NDA

\section{PTA Provisions Across 6 years}

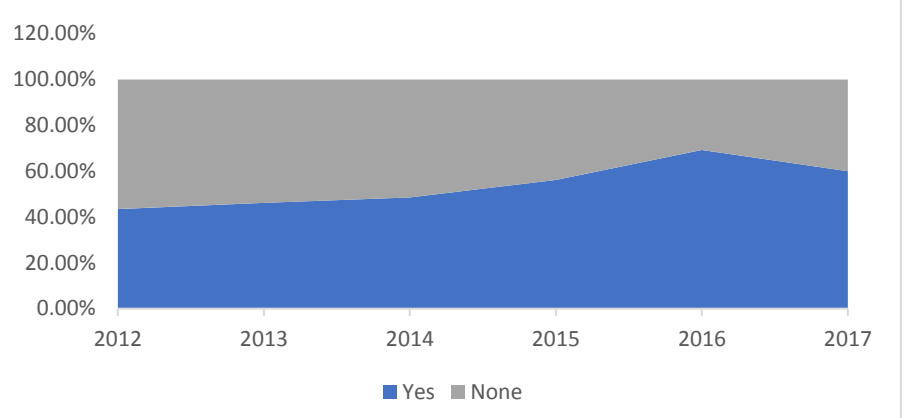

51
5
5
5
5
9

Figure 5: PTA according to type of study drug
Formatted: Font: $12 \mathrm{pt}$

\begin{tabular}{l} 
Formatted: Font: $12 \mathrm{pt}$ \\
\hline Formatted: Font: $12 \mathrm{pt}$ \\
Formatted: Font: $12 \mathrm{pt}$ \\
Formatted: Font: $12 \mathrm{pt}$ \\
\hline
\end{tabular}

Formatted: Font: $12 \mathrm{pt}$

Formatted: Font: $12 \mathrm{pt}$

Formatted: Font: $12 \mathrm{pt}$

Formatted: Font: $12 \mathrm{pt}$

Formatted: Font: $12 \mathrm{pt}$ 
PTA to be evaluated by sponsor depending on patient need; (5) unknown benefit owing to experimental nature of the study; (6) drug will be made/is available in the market; (7) option to transfer to open-label extension study; and (8) during-study access to study drug (Table $\underline{2}_{2}$ ).

\section{Type of Provisions by Year Submitted}

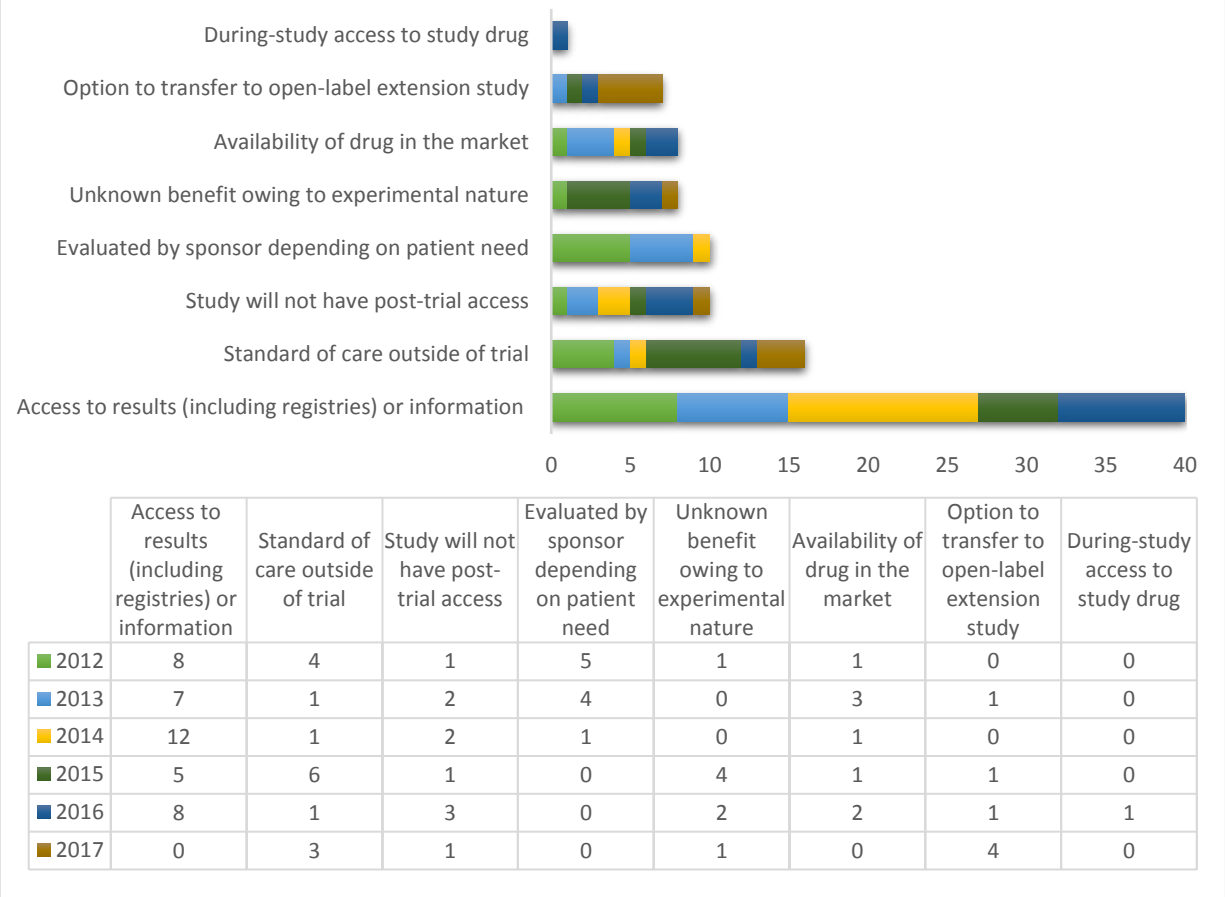

Table 23: Type of provisions by year of clinical trials submitted to UP Manilathe UPA-REB.

In Table 2,3, we se the most commonlyeommon PTA indicated PTA is access to results, including publication of results in a clinical trial registry or in medical journals, or the sharing of information, including safety information and other information that could potentially be useful in clinical decision-making. After access to information, the next commonlymost common. indicated PTA is the availability of standard of care outside of the trial as an alternative to trial participation. In practice, the IRB actively seeks the PTA provision only when the disease is rare or incurable or treatment is very expensive, and only when the results are effective and safe.

\section{Discussion}

\begin{tabular}{|l|}
\hline Formatted: Font: $12 \mathrm{pt}$ \\
\hline Formatted: Font: $12 \mathrm{pt}$ \\
\hline Formatted: Font: $12 \mathrm{pt}$ \\
\hline Formatted: Font: $12 \mathrm{pt}$ \\
\hline Formatted: Font: $12 \mathrm{pt}$ \\
\hline Formatted: Font: $12 \mathrm{pt}$ \\
\hline Formatted: Left, Space After: $0 \mathrm{pt}$ \\
\hline
\end{tabular}

\begin{tabular}{l} 
Formatted: Font: $12 \mathrm{pt}$ \\
\hline Formatted: Font: $12 \mathrm{pt}$ \\
\hline Formatted: Font: $12 \mathrm{pt}$ \\
\hline Formatted: Font: $12 \mathrm{pt}$ \\
\hline Formatted: Font: $12 \mathrm{pt}$ \\
\hline Formatted: Font: $12 \mathrm{pt}$ \\
\hline Formatted: Font: $12 \mathrm{pt}$ \\
\hline
\end{tabular}


178 The results of this study must be viewed in terms of the requirements of ethics guidelines, 179 specifically of the Declaration of Helsinki and $\mathrm{CIOMS}_{2}$ as quoted above. Helsinki requires the 180 sharing of knowledge, practices, or interventions; however, this declaration is silent on when 181 at time of PTA is relevant to which type of study. CIOMS provides more clarity in this matter ${ }_{2}$ 182 specifically, that Specifically, the requires. PTA is (to be-1) the responsibility of the sponsor 183 in cooperation with the government and other relevant stakeholders; and (2) this 184 responsibility consists in making the product developed and -knowledge generated to be, 185 available as soon as possible to the population or community where the research was carried 186 out.

187 The Declaration of Helsinki provision on post-trial access describes post-trial obligations as 188 189 190 191 providing access to appropriate care or to relevant information after research [6]. In the literature, access to appropriate care has been interpreted to mean affordable access or "reasonable availability of beneficial pharmaceuticals or medical treatments" [12]; continued access to study interventions that have demonstrated significant benefit and for transitioning participants who continue to need care and preventive measures after the research to appropriate health services [13]; or an obligation to facilitate sustainable access or subsidized access to new interventions in host communities [14].

In our study, several of the types of declared PTA by the sponsors showed that some sponsors either have their own definition of PTA that is different from what ethics guidelines provide, different from what the literature refers to as appropriate care, or that the sponsors have no idea what ethics guidelines or the literature say about PTA. The following PTA categories are either not in agreement with the ethical definition of PTA or are directly opposed to it: (1) presence of standard of care outside the trial; (2) no PTA of the study drug will be provided; (3) unknown benefit owing to experimental nature of the study; (4) drug will be made or is available in the market; and (5) during-study access to study drug.

The literature suggests that the practice of providing PTA differs across countries and contexts. The example of Brazil and Argentina, for example, refer to PTA as access to the interventional drug of the patient participants after the trial and so long as they need it and before access to other means becomes available [8]. This type of PTA was not directly observed in our study, though the 5\% (i.e., 10 of the 193) of the studies where PTA will be evaluated by the sponsor based on patient-participants' needs could lead to this sort of access. At the same time, PTA may also mean the transition of the patient-participants into extension studies sponsored by pharmaceutical manufacturers until the intervention becomes available in the health system $[13,15,16]$, though admittedly this is not always possible [17]. This was the case for $4 \%$ (i.e., 7 of the 193) of the clinical trials in our study. Lastly, the provision of PTA may also mean incorporating in the trial design the continued access to a proven beneficial intervention (e.g. WHO recommendations that PTA, in terms of availability of the vaccine to the community, be a requirement before conducting a clinical trial on a respiratory syncytial virus vaccine in LMICS) [18]. This type of PTA was not observed in our study.

\begin{tabular}{|l|}
\hline Formatted: Font: $12 \mathrm{pt}$ \\
\hline Formatted: Font: $12 \mathrm{pt}$ \\
\hline Formatted: Font: $12 \mathrm{pt}$ \\
\hline Formatted: Font: $12 \mathrm{pt}$ \\
\hline Formatted: Font: $12 \mathrm{pt}$ \\
\hline Formatted: Font: $12 \mathrm{pt}$ \\
\hline Formatted: Font: $12 \mathrm{pt}$ \\
\hline
\end{tabular}


The number of protocols that indicated PTA (51.81\%) among the clinical trials reviewed seemedsems encouraging, at first. However, when we consideredeonsider the types of PTA declared by the sponsors, we realized that the most that the population or community might get is information that may be clinically relevant in the future ( 40 protocols). In addition, there There, were sevenalso the 10 , protocols where the sponsor declared the future evaluation of PTA depending on patient need and another seven which might offer patient-participants the option to transfer to an open-label extension study, plus the 10 where PTA will be evaluated by the sponsor post-trial. In practice, sponsors provide post-trial access through follow-up studies to see long term effects on patients, open label extension studies, expanded access, and compassionate use, among others [9]. At best, these drugs are made available on a case to case basis [9] and not as a standard requirement to comply with the Declaration of Helsinki and CIOMS.

Out of the 100 protocols with post-trial provisions, there were 10 where the sponsor declared the future evaluation of PTA depending on patient need. This means that in all instances, none of the sponsors made PTA arrangements before the beginning of the study. Recall that CIOMS stipulates that before undertaking research in a community or population with limited resources, sponsors and investigators must "make every effort to ensure that any intervention or product developed, or knowledge generated, will be made reasonably available for the benefit of that population or community." From the perspective of CIOMS, only the 40 protocols that declared information sharing as PTA partially complied with the PTA imperative, and depending on how the sponsor decides on the situation, maybe the 17 others, too, who might consider PTA after sponsor evaluation or provide PTA in the form of an open-label follow up study. All others did not comply with PTA requirements at all.

Accordingsecond, several of the types of PTA that the sponsors declared shows that some sponsors either have their own definition of PTA that is different from what ethics guidelines provide, or that they have no idea what ethics guidelines say about PTA. The following PTA categories are either not in agreement with the ethical definition of PTA or are directly opposed to it: presence of standard of care outside the trial; no PTA of the study drug will be provided; unknown benefit owing to experimental nature of the study; drug will be made/is available in the market; and during-study access to study drug. Third, earlier mentioned that according to another study, pharmaceutical companies mostly provide PTA in "exceptional circumstances" (i.e., the situation is life-threatening; discontinuing treatment would result to adverse effect on health of the participant; no local alternative treatment; and a positive benefit-risk balance of the safety-efficacy of the treatment 2$)[9](8)$. Even when we narrowly define PTA this way, apparently none of the protocols saw the situation as exceptional enough to consider PTA pre-trial, and only 10 declared possible PTA subject to sponsor evaluation. This is a cause for concern because, first, at least some of the study drugs were meant to address diseases that could be life threatening such as the various kinds of neoplastic diseases or severe respiratory, autoimmune, or cardiovascular diseases. Second, we also know that a big proportion of the patient-participants of the UPA clinicat-trials

Formatted: Font: $12 \mathrm{pt}$
Formatted: Font: $12 \mathrm{pt}$
Formatted: Font: $12 \mathrm{pt}$
Formatted: Font: $12 \mathrm{pt}$
Formatted: Font: $12 \mathrm{pt}$
Formatted: Font: $12 \mathrm{pt}$

Formatted: Font: $12 \mathrm{pt}$

Formatted: Font: $12 \mathrm{pt}$

Formatted: Font: $12 \mathrm{pt}$

Formatted: Font: $12 \mathrm{pt}$

Formatted: Font: $12 \mathrm{pt}$

Formatted: Font: $12 \mathrm{pt}$ 
in UPM that were likely to discontinue with treatment, especially for very costly drugs, for several poverty-related reasons: there is no universal access to health care in the Philippines and health care is usually out of pocket; poverty rate is currently at 21.6\% \% [19](10); and the Philippine General Hospital of the UPM, as a public hospital, usually caters to patients who are unable to afford private hospitals.

Assuming that the study showed positive benefit/risk balance of efficacy-safety of the study drug, all the corporate indicators of what is "exceptional" seemed present in at least some of the studies. Since sponsors are usually aware of this situation, it must further be explored why none of the protocols considered PTA arrangements pre-trial, on the condition that there is positive benefit-risk balance of the safety-efficacy profile of the study drug, and only 10 indicated this probability subject to sponsor evaluation. Literature offers to explain noncompliance to PTA. According to Wang and Ferraz, commitment to post-trial obligations may be onerous and may impede future research, regardless of who will be sponsoring these obligations, as it may redirect costs from funding other potential studies such as chronic and rare diseases [20]. Whether this reason holds from an economic perspective remains to be seen.

ToAs such, to date, none of the clinical trial protocols evaluated by UPMREBUPM-REB fully complied with ethical requirements for PTA. Through no fault of the IRB, there remains a lack of standardized governance to implement post-trial obligations [21]. If PTA is to be fully reflected in reality, clearly morea lof work has to be done in terms of clarification of what the term means (i.e., what must be, provided, in what manner, to what extent); ensuring common understanding of the term among the various stakeholders; a PTA-encouraging environment; and a structure that facilitates stakeholder cooperation for PTA.

\section{Conclusion}

More than half (100 out of 193) of the clinical trials submitted in UPMREB indicated post-trial provisions and the most common post-trial access provision identified is access to information. Post-trial access will be dependent upon the evaluation of the sponsor based on patient need and the option to transfer to open-label extension study in ten (5\%) and seven (4\%) clinical trials, respectively. It can be deduced that none of the sponsors made PTA arrangements pretrial, and at best, are made available on a case to case basis. This result is alarming since these clinical trials involved life-threatening diseases, and especially for researches conducted in LMICs where there is no adequate access to marketed drugs and even to universal health care, patients may not be able to access these drugs after the trial ends. As such, post-trial access to study drugs remains a challenge. There are existing guidelines stipulating post-trial obligations but there is poor compliance among the pharmaceutical sponsors. Furthermore, despite the ClOMS and Helsinki provisions on post-trial access, there seems to be no international consensus around it. Based on its current status, achieving post-trial access, as stipulated in ethics guidelines, would need further and considerable work. Of the 193 study protocols reved by UPA-REB, $51.81 \%$ indicated PTA, but none of them fully complied with the PTA requirements as

\begin{tabular}{|l|} 
Formatted: Font: $12 \mathrm{pt}$ \\
Formatted: Font: $12 \mathrm{pt}$ \\
Formatted: Font: $12 \mathrm{pt}$ \\
Formatted: Font: $12 \mathrm{pt}$, Underline \\
Formatted: Font: $12 \mathrm{pt}$ \\
Formatted: Font: $12 \mathrm{pt}$ \\
Formatted: Font: $12 \mathrm{pt}$ \\
Formatted: Font: $12 \mathrm{pt}$ \\
Formatted: Font: $12 \mathrm{pt}$ \\
\hline Formatted: Font: $12 \mathrm{pt}$ \\
\hline
\end{tabular}


stipulated in ethics guidelines. A lot of work needs to be done if PTA, as stipulated in ethics guidelines, is to be fully reflected in reality.

\section{Declaration}

The research leading to these results has received funding from the European Union Seventh 300 Framework Programme (FP7-PEOPLE-2013-COFUND) under grant agreement $n^{\circ} 609020$ 301 Scientia Fellows.

\section{References:}

[1] 1. Eccard R, Amato AA, Guilhem DB, Rita M, Garbi C, Silva RE. Globalization of clinical trials : ethical and regulatory implications. Int J Clin Trials (fInternet)... 2016;3(1):1-8. Available from: http://www.ijclinicaltrials.com/index.php/ijct/article/view/103

[2] Z. Glickman SW, McHutchison JG, Peterson ED, Cairns CB, Harrington RA, Califf RM, et al. Ethical and Scientific Implications of the Globalization of Clinical Research. N Engl J Med (fInternet).]. 2009;360[9]:(8):816-23. Available from: http://www.nejm.org/doi/abs/10.1056/NEJMsb0803929

[3] 3. Jeong S, Sohn M, Kim JH, Ko M, Seo H won, Song YK, et al. Current globalization of drug interventional clinical trials: Characteristics and associated factors, 2011-2013. Trials. 2017;

[4] 4. European Medicines Agency. Clinical trials submitted in marketing authorization applications to the European Medicines Agency: overview of patient recruitment and the geographical location of investigator sites (fInternet).. 2013. Available from: http://www.ema.europa.eu/docs/en_GB/document_library/Other/2009/12/WC500016 819.pdf

[5] 5. Wemos Foundation. A bitter pill: the risks of carrying out clinical trials in developing countries (fInternet).]. Amsterdam; 2008. Available from: https://www.wemos.nl/wp-content/uploads/2017/04/A_Bitter_Pill_2008.pdf

[6] 6. Association WM. Declaration of Helsinki - ethical principles for medical research involving human subjects (fInternet).\}. 2013 (fcited 2015 Apr 20).\}. Available from: http://www.wma.net/en/30publications/10policies/b3/

[7] 7. Council for International Organizations of Medical Sciences. International ethical guidelines for health-related research involving humans (fInternet).f. 2016. Available from: https://cioms.ch/shop/product/international-ethical-guidelines-for-healthrelated-research-involving-humans/

[8] da Silva RE, Amato AA, Sousa TdR, de Carvalho MR, Novaes MRCG. The patient's safety and access to experimental drugs after the termination of clinical trials: regulations and trends. European Journal of Clinical Pharmacology. 2018.

[9] 8. Schipper I. Post-trial access to treatment: corporate best practices (flnternet).]. . Amsterdam; 2015. Available from: http://www.somo.nl/publications-
Formatted: Font: $12 \mathrm{pt}$

Formatted: Font: (Default) +Body (Calibri), 12 pt

Formatted: Font: $12 \mathrm{pt}$

Formatted: List Paragraph, Indent: Hanging: 0.5", Numbered + Level: 1 + Numbering Style: $1,2,3, \ldots+$ Start at: $1+$ Alignment: Left + Aligned at: $0.25 "+$ Indent at: 0.5", Pattern: Clear (Background 1)

Formatted: List Paragraph, Indent: Hanging: $0.5^{\prime \prime}$ Numbered + Level: 1 + Numbering Style: $1,2,3, \ldots+$ Start at: 1 + Alignment: Left + Aligned at: $0.25 "+$ Indent at: $0.5 "$, Pattern: Clear (Background 1) 
en/Publication_4169

9. Páez R, De Alba JEG. International research and just sharing of benefits in Mexico. Dev World Bioeth. 2009;9(2):65-73.

10. Asian Development Bank. Poverty in the Philippines [Internet]. 2018. Available from: https://www.adb.org/countries/philippines/poverty

\section{[11] 11. US Center for Drug Evaluation and Research. NDA Classification Codes} (flnternet).]. 2015. Available from: https://www.fda.gov/downloads/AboutFDA/CentersOffices/OfficeofMedicalProductsan dTobacco/CDER/ManualofPoliciesProcedures/UCM470773.pdf

[12] Cook K, Snyder J, Calvert J. Attitudes toward post-trial access to medical interventions: A review of academic literature, legislation, and international guidelines. Developing World Bioethics. 2015.

[13] Paul A, Merritt MW, \& Sugarman J. Implementing post-trial access plans for HIV prevention research. 2018.

[14] Pratt B, Zion D, Lwin KM, Cheah PY, Nosten F, Loff B. Linking international clinical research with stateless populations to justice in global health. BMC Medical Ethics. 2014;15:49. Available from: https://www.ncbi.nIm.nih.gov/pmc/articles/PMC4085396/pdf/1472-6939-15-49.pdf

[15] Doval DC, Shirali, R, Sinha R. Post-trial access to treatment for patients participating in clinical trials. Perspectives in Clinical Research. 2015;6(2): 82-85.

[16] Usharani P, Nagyi, SMH. Post-trial access. Perspectives in Clinical Research. 2013;4(1):58-60. Available from: https://www.ncbi.nlm.nih.gov/pmc/articles/PMC4394585/

[17] Dainesi SM, Goldbaum M. Post-trial access to study medication: a Brazilian e-survey with major stakeholders in clinical research. Journal of Medical Ethics. 2012.

[18] Mazur NI, Bont LJ, van Delden JJM, Omer SB. An ethics framework and practical guidance for post-trial access to an RSV maternal vaccine. 2019. The Lancet Respiratory Medicine.

[19] Asian Development Bank. Poverty in the Philippines (Internet). 2018. Available from: https://www.adb.org/countries/philippines/poverty

[20] Wang DWL, and Ferraz OLM. Pharmaceuitcal companies vs the State: Who is responsible for post-trial provision of drugs in Brazil? 2012. Journal of Law, Medicine \& Ethics.

[21] Mastroleo, I. Post-trial obligations in the Declaration of Helsinki 2013: Classification, reconstruction, and interpretation. 2015.
Formatted: List Paragraph, Indent: Hanging: 0.5 " Numbered + Level: 1 + Numbering Style: $1,2,3, \ldots+$ Start at: 1 + Alignment: Left + Aligned at: $0.25^{\prime \prime}+$ Indent at: $0.5 "$, Pattern: Clear (Background 1)

Formatted: List Paragraph, Indent: Hanging: $0.5^{\prime \prime}$ Numbered + Level: 1 + Numbering Style: 1, 2, 3, ... Start at: 1 + Alignment: Left + Aligned at: $0.25 "+$ Indent at: $0.5^{\prime \prime}$

Formatted: Font: $12 \mathrm{pt}$

Formatted: Font: $12 \mathrm{pt}$ 